\title{
An Exploratory Analysis of the Portrayal of Mental Illness in Qatar's Newspapers
}

This article was published in the following Dove Press journal:

Psychology Research and Behavior Management

\author{
Monica Zolezzi (iD) \\ Sara Elshami' \\ Warda Obaidi ${ }^{2}$ \\ 'Clinical Pharmacy and Practice, College \\ of Pharmacy, QU Health, Qatar \\ University, Doha, Qatar; ${ }^{2}$ Pharmacy \\ Department, Hamad Medical \\ Corporation, Doha, Qatar
}

Background: Concerns have been raised about the role of the media influencing the public's understanding of mental illness.

Aim: This study explored the extent and nature of mental health coverage in Qatar's newspapers. A secondary aim was to compare the mental health-related coverage with that of diabetes.

Methods: This was a retrospective quantitative and qualitative analysis of textual data published in Qatari newspapers. Quantitative descriptive analysis was employed to determine the extent of media coverage while qualitative content analysis was employed to examine the discourse tone and assess the stigmatization of the main messages on the text.

Results: A total of 659 mental health-related articles were published; the main focus of the articles was on autism, depression, and non-pharmacological therapies for mental illness. Analysis of the retrieved articles revealed a predominantly informative content, with mostly non-stigmatizing tone except for non-national news that often linked mental illness with dangerousness or violence. A higher number of articles with mental health-related content than about diabetes were found.

Conclusion: Although the newspaper content analysis revealed mostly a non-stigmatizing tone in mental health reporting in newspapers, there is a need to increase representation of people with mental illness in print media, increase awareness of the diversity of treatments available, and increase more scientific reporting to raise mental health literacy in Qatar.

Keywords: mental health, newspapers, portrayal, media, stigma

\section{Background}

According to the World Health Organization (WHO), mental disorders comprise a broad range of problems with different symptoms that are generally characterized by some combination of abnormal thoughts, emotions, behavior and relationships with others. ${ }^{1}$ Recent worldwide reports suggest that mental and addictive disorders affect more than one billion people globally, with depression causing most disability. ${ }^{2}$ Unfortunately, many people do not recognize the symptoms associated with mental disorders and consequently do not access treatment. ${ }^{3}$ It has been suggested that nearly two-thirds of people with a known mental disorder never seek help from a health professional. ${ }^{4}$ Although this may be multifactorial, evidence suggests that stigma, discrimination and neglect prevent care and treatment from reaching people with mental illness.,3 Several studies have demonstrated that media often presents people with mental illness negatively, linking them with acts of violence, crime, dangerousness and disability, promoting public stigma. ${ }^{5}$
Clinical Pharmacy and Practice, College of Pharmacy, QU Health, Qatar University, PO Box 27I3, Doha, Qatar

Tel +97444035623

Fax +974 4403555 I

Email mzolezzi@qu.edu.qa
Psychology Research and Behavior Management 2020:13 1323-1332 DovePres: in $\mathbf{P}$ 
In the mental health context, public stigma occurs when members of the general public endorse stereotypes about mental illness and act on the basis of these stereotypes. It refers to a cluster of negative attitudes and beliefs that motivate the general public to fear, reject, avoid and discriminate against the mental ill. ${ }^{6}$ As a result of mental health stigma, the service and treatment gaps for an already underserved population widen, leaving individuals with mental illness having to cope not only with the burden and disability associated with their symptoms but also with the societal stigmatization of their illness. ${ }^{7,8}$ Relatively recent reports suggest that stigma toward people with mental illness exists to a substantial extent among Arabs in the Middle East. ${ }^{9,10}$

Qatar has a comparable prevalence of mental illnesses to those in other countries worldwide. According to Qatar's Ministry of Public Health (MOPH), approximately one in five people in Qatar is estimated to be affected by mental illness at any given point in time. ${ }^{11}$ Studies conducted on Qatar's population to assess their knowledge, attitudes and behaviors towards mental illness are indicative that most people have poor mental health literacy, insufficient information about the causes and symptoms of mental illness, and stigmatized perceptions towards people with mental illness. ${ }^{12-14}$ Thus, in order to reduce stigma and encourage access to mental health services, the provision of accurate information about mental illness and its treatment is crucial. Qatar's MOPH identifies the media as a key vehicle to achieve their goals in relation to improving the population's mental health literacy. ${ }^{11}$ Responsible media can be an important ally in increasing the public's knowledge, especially on poorly understood mental health topics. As a result, many countries have engaged public health specialists with media professionals in awareness campaigns to ensure destigmatized coverage about mental health is provided. ${ }^{15,16}$

There has been limited information on the portrayal of mental illness in the Qatar media. Elzamzamy and colleagues recently reported an overview of the extent, nature and quality of reporting on mental health compared with physical health in Qatari newspapers. ${ }^{17}$ Although the study only examined articles published in a 2-month period, the results pointed to an overall under-representation of mental health in Qatari newspapers. In addition, the study did not examine coverage of mental health treatments. In this article, we present the results of a similar study, which provides additional information on the portrayal of mental health in English and Arabic Qatari newspapers after a year-round retrospective quantitative and qualitative content analysis.

\section{Methods}

A retrospective quantitative and qualitative content analysis approach of textual data published in Qatari newspapers between January and December of 2017 was used. Quantitative descriptive analysis was employed to determine the extent of media coverage while qualitative content analysis was employed to examine the discourse tone and assess the stigmatization of the main messages on the text.

\section{Publication Selection}

Two Arabic and two English daily newspapers with the highest circulation and reputation were selected to compare mental health coverage between Arabic and English newspapers and to ensure broader extraction of articles. The chosen Arabic newspapers were Al-Raya (circulation: 25,000/day) and Al-Watan (circulation: 13,600/day), whilst English newspapers were Gulf-Times (circulation: 22,000/ day) and Qatar Tribune (circulation: 15,000/day). The electronic archives were used for article screening from Gulf Times and Al-Raya newspapers as PDF files, while for Qatar Tribune and Al-Watan, printed newspaper copies were used.

\section{Inclusion/Exclusion Criteria}

Articles were included if they reported about mental health generally and/or about specific mental disorders. The National Alliance on Mental Illness (NAMI) classification was used for defining mental health disorders which include anxiety disorders, attention deficit hyperactivity disorder, autism, bipolar disorder, borderline personality disorder, depression, dissociative disorder, psychosis, eating disorders, obsessive-compulsive disorders, post-traumatic disorder, schizophrenia, suicide and self-harm. ${ }^{18}$ Articles were included if mental health/illness was either a central or a subordinate theme of the article.

Only the "main" and "supplement" sections of newspapers were included in the screening process. There was neither a restriction of the article's size nor the word count. The exclusion criteria were "sports" and "business" sections of the newspapers, advertisements, wedding announcements, obituaries, repeated news in the same newspaper, articles that talks about physical and mental disability together and metaphorically used mental illnessrelated words. 


\section{Search Strategy}

The research was conducted in 2018, but daily newspapers from the previous year (2017) were included in the search. Screening for eligible articles that mention mental healthrelated topics was done by two investigators (SE and WO). For printed newspaper copies, article titles were screened manually, whereas keywords were used for searching the electronic copies. The search terms used included "mental", "psych", "autis", "depress", "ADHD”, "schizo", "anxi", "bipolar", "eating", "trauma", "drug" and "treat". The same terms were translated into Arabic for electronic Arabic newspapers.

\section{Analysis}

Data extraction sheets (for both languages) were developed and coded articles in three main categories. First, article identification (4 items) where articles were coded for their newspaper origin, date, and section of the newspaper (main or supplement). Second, level of attractiveness and interest given to mental health topics ( 8 items) based on previously established criteria, including the article location, the length of the article, the heading font size and color, distinction in article formatting, and the display of images if present. ${ }^{19}$ Third, content analysis of the article title and text ( 8 items) to extract the main theme or idea conveyed and the overall impression about the portrayal of mental illness was based on a modified version of a coding schema that was used in a similar study which explored newspaper depictions of mental and physical health. ${ }^{20}$ In addition, articles were also analyzed for their types (news, events, educational, etc.), the source of the news (national or international), specified mental illness and treatment, and if they included a quotation and its source.

The data extraction sheets were built using SurveyMonkey ${ }^{\circledR}$ (Survey Monkey Inc., San Mateo, California, USA) and piloted prior to being used. They were filled independently by two investigators (SE and WO). Counts and frequencies were determined for each item. To maintain consistency, the research investigators were trained for the intended meaning of each item and the definition of each option before the actual study conduction. Any uncertainty in filling the data collection sheet was further resolved by consensus with a third investigator (MZ).

To assess if there were any differences in the extent of mental health coverage compared with a similarly highly prevalent physical condition in Qatar, such as diabetes mellitus (DM), the Qatar-Tribune newspaper was screened over a one-year period. It has been reported that the prevalence of DM in the Qatari adult population is approximately $17 \%{ }^{21}$ This incidence is similar to the prevalence of mental health disorders in Qatar (approximately 20\%). ${ }^{11}$ Qatar Tribune was the only newspaper that had a full availability of issues at the time of conducting the comparison. The search strategy applied for mental health topics was followed for diabetes-related article screening and data extraction. The included articles were surveyed using the pre-developed data extraction sheet after modification for the purpose of diabetes content analysis.

\section{Ethical Approval}

Ethics approval for the conduct of the study was not required as the data were obtained from an open source (newspapers published in public domains).

\section{Results}

A total of 659 articles were retrieved from the selected newspapers, 310 were found in English newspapers (Gulf Times $n=183$ and Qatar-Tribune $n=127$ ) and 349 in Arabic newspapers (Al Raya $n=247$ and Al Watan $n=102$ ). The average number of articles per month was 55 . The months of April and October had the highest mental health-related coverage. The majority of the articles were published in the main section of the newspaper, although almost a quarter of articles in English newspapers were found in the supplement section.

Presence of mental health articles in the first or last pages was less than $10 \%$ in both language newspapers, and only around $20 \%$ of the articles occupied more than half of the page. Although the majority of the articles were small in size, large font size were used in the headlines. However, most headlines in both language newspapers were printed in black ink. About half of the articles in Arabic newspapers were displayed in a special format such as bordered or colored background. Almost two-thirds of articles in both language newspapers included images, mostly were of large size. In the majority of articles, the images provided a neutral impression.

The majority (44\%) of mental health articles retrieved were in relation to general news. National news were mostly found in Arabic newspapers; whereas both, national and international news, were equally reported in English newspapers. Informative reports were published frequently on both language newspapers with themes such as "causes" and "symptoms" predominating. Only a few 
articles presented opinions of the general public or stories of people with mental illness and/or their families, and these were mostly published in English newspapers.

More than half of the articles from both language newspapers reported on a specific mental disorder such as autism spectrum disorder, depression, and anxiety disorders. Other disorders like schizophrenia, bipolar disorder, eating disorder, attention deficit hyperactivity disorder, post-traumatic stress disorder, obsessivecompulsive disorder, and personality disorder had minimal coverage. A relatively large proportion of articles retrieved from both language newspapers were about treatments, the focus of these articles was mainly on nonpharmacological therapies. There was limited coverage in relation to religious or spiritual healing on both language newspapers.

The majority of articles in both English and Arabic newspapers used quotations to support mental healthrelated topics. The majority of these were quotes from experts in the field of mental health, while only a few were from people with mental illness or their families. The majority of articles (65\%) displayed a neutral and non-stigmatizing portrayal of mental illness and its treatments. A more detailed description of the mental health coverage in English and Arabic newspapers is presented in Table 1.

\section{Comparison of Mental Health/IIIness Coverage with Diabetes}

Of the 179 articles extracted from Qatar Tribune over the 12-month period, 127 were related to mental health and 52 to DM, with an average number of 11 and 4 articles per month, respectively. Coverage of mental health topics remained highest in the month of April, whereas November was the highest for DM. The overall level of attractiveness of the articles covering mental health and DM topics was similar. The majority of the published articles on DM were informative reports, whereas mental health coverage was mostly related to general news. Event-related articles were more about DM than about mental health. Although mental health articles had more general treatment-related content, articles about DM emphasized on the side effects of medications. Both, mental health and DM articles displayed a similar written discourse tone, which was assessed mostly as being neutral $(75.6 \%$ of mental health articles versus $65.4 \%$ of DM articles). A more detailed comparison between the newspaper coverage of mental illness and DM is presented in Table 2.

\section{Discussion}

The key finding of this study, which systematically reviewed mental health coverage in Qatari newspapers for a period of one year, revealed a predominance of general news, with a written discourse tone considered as neutral and non-stigmatizing, except for non-national news that often linked mental illness with dangerousness or violence. In a recently published study by Elzamzamy and colleagues, who reviewed Qatari newspaper articles in a two-month period one year after, similar results were reported. ${ }^{17}$ In their study, they also reported the majority of the articles provided general mental health information and were either positive or neutral in tone. However, and in contrast to our findings, the study by Elzamzamy and colleagues also found almost three times more articles reporting on physical health than about mental illness. As our review only included DM, it is difficult to ascertain that their findings are truly different than ours, considering the wide range of possible physical illnesses that were covered in their review. Together, these findings are indicative that there appears to be a progressive intent in the Qatar media to increase mental health coverage and to portray mental illness less negatively than what has been previously reported in other countries around the world. ${ }^{22-24}$

Several issues were analyzed which may further explain the above key findings. First, that in Qatar, newspaper reporting on mental illness is influenced by current worldwide events. This study results indicate that mental health content was more prominent in the months of April and October. This was likely linked to external events such as the "World Autism Day" and the "World Mental Health Day" which every year are scheduled in the months of April and October, respectively. Mental health coverage was notably lower in the month of June, most likely due to an important political event that occurred in Qatar in June 2017; specifically, the economic blockade imposed on Qatar by other Arabian Gulf countries. The higher number of articles about autism and depression that were found in this review was also possibly linked to important mental health-related events that were launched in 2017, the year this study was conducted, including the Qatar National Autism Plan and the World Mental Health Day campaign "Depression: 
Table I Mental Health Coverage in English and Arabic Newspapers

\begin{tabular}{|c|c|c|c|}
\hline Assessment Item & English Newspapers N (\%) & Arabic Newspapers N (\%) & Total N (\%) \\
\hline \multicolumn{4}{|l|}{ Publication month } \\
\hline January & $18(5.8 \%)$ & 40 (11.5\%) & $58(8.8 \%)$ \\
\hline February & $18(5.8 \%)$ & 30 (8.6\%) & $48(7.3 \%)$ \\
\hline March & $25(8.1 \%)$ & $46(13.2 \%)$ & 71 (10.8\%) \\
\hline April & 71 (22.9\%) & $55(15.7 \%)$ & $126(19.1 \%)$ \\
\hline May & $27(8.7 \%)$ & $4 \mid(11.8 \%)$ & $68(10.3 \%)$ \\
\hline June & $15(4.8 \%)$ & $24(6.9 \%)$ & 39 (5.9\%) \\
\hline July & $26(8.4 \%)$ & $12(3.4 \%)$ & $38(5.8 \%)$ \\
\hline August & $12(3.9 \%)$ & 18 (5.2\%) & $30(4.6 \%)$ \\
\hline September & $16(5.2 \%)$ & II (3.2\%) & 27 (4.1\%) \\
\hline October & $44(14.2 \%)$ & 34 (9.7\%) & $78(11.8 \%)$ \\
\hline November & $22(7.1 \%)$ & $22(6.3 \%)$ & $44(6.7 \%)$ \\
\hline December & $16(5.2 \%)$ & $16(4.6 \%)$ & $32(4.9 \%)$ \\
\hline \multicolumn{4}{|l|}{ Newspaper section } \\
\hline Main & 237 (76.5\%) & 345 (98.9\%) & $582(88.3 \%)$ \\
\hline Supplement & $73(23.6 \%)$ & $4(1.2 \%)$ & 77 (11.7\%) \\
\hline \multicolumn{4}{|l|}{ Attractiveness } \\
\hline \multicolumn{4}{|l|}{ Page } \\
\hline Front & $16(5.2 \%)$ & $12(3.4 \%)$ & $28(4.3 \%)$ \\
\hline Back/Last & $7(2.3 \%)$ & 17 (4.9\%) & $24(3.6 \%)$ \\
\hline Any other page & $287(92.6 \%)$ & 320 (91.7\%) & 607 (92.1\%) \\
\hline \multicolumn{4}{|l|}{ Length } \\
\hline$\geq$ Half-page & $70(22.6 \%)$ & $68(19.5 \%)$ & 138 (20.9\%) \\
\hline$<$ Half-page & $240(77.4 \%)$ & $28 \mid(80.5 \%)$ & $521(79.1 \%)$ \\
\hline \multicolumn{4}{|l|}{ Heading font color } \\
\hline Black & $250(80.7 \%)$ & $234(67.1 \%)$ & 484 (73.4\%) \\
\hline Maroon & 14 (4.5\%) & $88(25.2 \%)$ & $102(15.5 \%)$ \\
\hline Other & $46(14.8 \%)$ & $27(7.7 \%)$ & $73(11.1 \%)$ \\
\hline \multicolumn{4}{|l|}{ Heading font size } \\
\hline Bigger than others & $107(34.5 \%)$ & $129(37 \%)$ & $236(35.8 \%)$ \\
\hline Same as others & $116(37.4 \%)$ & $153(43.8 \%)$ & $269(40.8 \%)$ \\
\hline Smaller than others & $87(28.1 \%)$ & 67 (19.2\%) & $154(23.4 \%)$ \\
\hline \multicolumn{4}{|l|}{ Article format* } \\
\hline Bordered & $12(3.9 \%)$ & 101 (28.9\%) & $113(17.2 \%)$ \\
\hline Solid background color & $49(15.8 \%)$ & $105(30.1 \%)$ & 154 (23.4\%) \\
\hline Standard & $252(81.3 \%)$ & 179 (51.3\%) & 431 (65.4\%) \\
\hline \multicolumn{4}{|l|}{ Presence of image } \\
\hline Yes & $|8|$ (58.4\%) & $26 \mathrm{I}(74.8 \%)$ & $442(67.1 \%)$ \\
\hline No & $129(41.6 \%)$ & 88 (25.2\%) & $217(32.9 \%)$ \\
\hline \multicolumn{4}{|l|}{ Image size } \\
\hline Big ( $\geq$ half of the article) & $98(54.1 \%)$ & $120(46 \%)$ & $218(49.3 \%)$ \\
\hline Small $(<$ half of the article) & $83(45.9 \%)$ & $|4|(54 \%)$ & $224(50.7 \%)$ \\
\hline \multicolumn{4}{|l|}{ Image Impression } \\
\hline Positive & $24(13.3 \%)$ & $20(7.7 \%)$ & 44 (10\%) \\
\hline Neutral & 149 (82.3\%) & $233(89.3 \%)$ & $382(86 \%)$ \\
\hline Negative & $10(5.5 \%)$ & $9(3.5 \%)$ & $19(4 \%)$ \\
\hline
\end{tabular}


Table I (Continued).

\begin{tabular}{|c|c|c|c|}
\hline Assessment Item & English Newspapers N (\%) & Arabic Newspapers N (\%) & Total N (\%) \\
\hline \multicolumn{4}{|l|}{ Content analysis } \\
\hline \multicolumn{4}{|l|}{ Article type* } \\
\hline General news & 157 (50.7\%) & $133(38.1 \%)$ & $290(44.0 \%)$ \\
\hline Awareness & $43(13.9 \%)$ & $82(23.5 \%)$ & $125(19 \%)$ \\
\hline MH services & 40 (12.9\%) & $43(12.3 \%)$ & $83(12.6 \%)$ \\
\hline Informative report & $93(30 \%)$ & $88(25.2 \%)$ & $18 \mid(27.5 \%)$ \\
\hline Commentary & $12(3.9 \%)$ & $32(9.2 \%)$ & $44(6.7 \%)$ \\
\hline Personal stories & $9(2.9 \%)$ & $0(0.0 \%)$ & $9(1.4 \%)$ \\
\hline Other & $14(4.5 \%)$ & $21(6.0 \%)$ & $35(5.3 \%)$ \\
\hline \multicolumn{4}{|l|}{ News source* } \\
\hline National & $113(36.5 \%)$ & $190(54.8 \%)$ & $303(46 \%)$ \\
\hline International & $112(36.1 \%)$ & $61(17.6 \%)$ & $173(26.3 \%)$ \\
\hline Not applicable & $85(27.4 \%)$ & $96(27.7 \%)$ & 181 (27.5\%) \\
\hline \multicolumn{4}{|l|}{ Article topics* } \\
\hline MH care system/service & $67(21.6 \%)$ & $107(30.7 \%)$ & $174(26.4 \%)$ \\
\hline MH events & $52(16.8 \%)$ & $75(21.5 \%)$ & $127(19.3 \%)$ \\
\hline Causes & $52(16.8 \%)$ & $54(15.5 \%)$ & $106(16.1 \%)$ \\
\hline Treatments & 91 (29.4\%) & $47(13.5 \%)$ & $138(20.9 \%)$ \\
\hline Symptoms & $45(14.5 \%)$ & $86(24.6 \%)$ & $13 \mid(19.9 \%)$ \\
\hline Side effects of treatments & $2(0.7 \%)$ & $8(2.3 \%)$ & $10(1.5 \%)$ \\
\hline Dangerousness & $48(I 5.5 \%)$ & $29(8.3 \%)$ & $77(11.7 \%)$ \\
\hline Stigma & $36(11.6 \%)$ & $11(3.2 \%)$ & $47(7.1 \%)$ \\
\hline Other & $105(33.9 \%)$ & $86(24.6 \%)$ & 191 (29\%) \\
\hline \multicolumn{4}{|l|}{ Type of mental illness* } \\
\hline Unspecified (general) & $112(36.1 \%)$ & $137(39.3 \%)$ & $249(37.8 \%)$ \\
\hline Autism & $79(25.5 \%)$ & $92(26.4 \%)$ & $17 \mid(26 \%)$ \\
\hline Depression & $68(21.9 \%)$ & 87 (24.9\%) & $155(23.5 \%)$ \\
\hline Anxiety/panic disorders & $34(11 \%)$ & $21(6 \%)$ & $55(08.4 \%)$ \\
\hline \multicolumn{4}{|l|}{ Type of mental illness treatment* } \\
\hline Alternative therapy & $35(11.3 \%)$ & $25(7.2 \%)$ & $60(9.1 \%)$ \\
\hline Religious/spiritual healing & $3(1 \%)$ & $8(2.3 \%)$ & II (I.7\%) \\
\hline Cognitive behavioral therapy & $28(9.3 \%)$ & $38(10.9 \%)$ & $66(10.0 \%)$ \\
\hline General medications & $26(8.4 \%)$ & $25(7.2 \%)$ & $51(7.7 \%)$ \\
\hline Specific medication & $2(0.7 \%)$ & $5(1.4 \%)$ & $7(1.1 \%)$ \\
\hline Other & $17(5.5 \%)$ & $32(9.2 \%)$ & $49(7.4 \%)$ \\
\hline Not applicable & $222(71.6 \%)$ & $250(71.6 \%)$ & $472(71.6 \%)$ \\
\hline \multicolumn{4}{|l|}{ Included quotation(s) } \\
\hline Yes & $258(83.2 \%)$ & $212(60.7 \%)$ & $470(71.3 \%)$ \\
\hline No & $52(16.8 \%)$ & $137(39.3 \%)$ & $189(28.7 \%)$ \\
\hline \multicolumn{4}{|l|}{ Source of quotation(s)* } \\
\hline Expert & $182(70.5 \%)$ & $165(77.8 \%)$ & $347(73.8 \%)$ \\
\hline People with mental illness & $14(5.4 \%)$ & $7(3.3 \%)$ & $21(4.4 \%)$ \\
\hline Family/friends & $20(7.8 \%)$ & $15(7.1 \%)$ & $35(7.4 \%)$ \\
\hline Others & $102(39.5 \%)$ & $47(22.2 \%)$ & $149(31.7 \%)$ \\
\hline \multicolumn{4}{|l|}{ Overall impression/Discourse tone } \\
\hline Positive & $83(26.8 \%)$ & $99(28.4 \%)$ & $182(27.6 \%)$ \\
\hline Neutral & $197(63.6 \%)$ & $231(66.2 \%)$ & $428(65 \%)$ \\
\hline Negative & $30(9.7 \%)$ & $19(5.4 \%)$ & $49(7.4 \%)$ \\
\hline
\end{tabular}

Note: *Multiple answers are possible.

Abbreviations: $\mathrm{N}$, number of articles; \%, percentage; $\mathrm{MH}$, mental health. 
Table 2 Mental Health versus Diabetes Mellitus Coverage in the Qatar Tribune

\begin{tabular}{|c|c|c|}
\hline Assessment Item & $\begin{array}{l}\text { Mental } \\
\text { Health } \\
\text { N (\%) }\end{array}$ & $\begin{array}{l}\text { Diabetes } \\
\text { Mellitus N (\%) }\end{array}$ \\
\hline \multicolumn{3}{|l|}{ Publication month } \\
\hline \multicolumn{3}{|l|}{ Month } \\
\hline January & 9 (7.1\%) & $6(11.5 \%)$ \\
\hline February & 7 (5.5\%) & $5(9.6 \%)$ \\
\hline March & 10 (7.9\%) & $4(7.7 \%)$ \\
\hline April & 27 (21.3\%) & I (1.9\%) \\
\hline May & $13(10.2 \%)$ & $5(9.6 \%)$ \\
\hline June & $4(3.2 \%)$ & I (1.9\%) \\
\hline July & $12(9.5 \%)$ & $0(0.0 \%)$ \\
\hline August & $6(4.7 \%)$ & $2(3.9 \%)$ \\
\hline September & $7(5.5 \%)$ & $0(0.0 \%)$ \\
\hline October & $16(12.6 \%)$ & $4(7.7 \%)$ \\
\hline November & $9(7.1 \%)$ & $18(34.6 \%)$ \\
\hline December & $7(5.5 \%)$ & $6(11.5 \%)$ \\
\hline \multicolumn{3}{|l|}{ Newspaper section } \\
\hline Main & 79 (62.2\%) & $42(80.8 \%)$ \\
\hline Supplement & 48 (37.8\%) & $4(19.2 \%)$ \\
\hline \multicolumn{3}{|l|}{ Attractiveness } \\
\hline \multicolumn{3}{|l|}{ Page } \\
\hline Front & $8(6.3 \%)$ & $\mathrm{I}(1.9 \%)$ \\
\hline Back/Last & $5(3.9 \%)$ & I (1.9\%) \\
\hline Any other page & 114 (89.8\%) & $50(96.2 \%)$ \\
\hline \multicolumn{3}{|l|}{ Length } \\
\hline$\geq$ Half-page & 40 (3I.5\%) & 10 (19.2\%) \\
\hline$<$ Half-page & 87 (68.5\%) & $42(80.8 \%)$ \\
\hline \multicolumn{3}{|l|}{ Heading font color } \\
\hline Black & 94 (74.0\%) & 43 (8279\%) \\
\hline Maroon & $6(4.7 \%)$ & $2(3.9 \%)$ \\
\hline Other & 27 (21.3\%) & 7 (13.5\%) \\
\hline \multicolumn{3}{|l|}{ Heading font size } \\
\hline Bigger than others & $42(33.1 \%)$ & $20(38.5 \%)$ \\
\hline Same as others & $28(22.0 \%)$ & 18 (34.6\%) \\
\hline Smaller than others & 57 (44.9\%) & 14 (26.9\%) \\
\hline \multicolumn{3}{|l|}{ Article format* } \\
\hline Bordered & II (8.7\%) & 10 (19.2\%) \\
\hline Solid background color & $32(25.2 \%)$ & 7 (13.5\%) \\
\hline Standard & $43(33.9 \%)$ & $36(69.2 \%)$ \\
\hline \multicolumn{3}{|l|}{ Presence of image } \\
\hline Yes & 91 (7I.7\%) & $33(63.5 \%)$ \\
\hline No & $36(28.3 \%)$ & $19(36.5 \%)$ \\
\hline \multicolumn{3}{|l|}{ Image size } \\
\hline Big ( $\geq$ half of the article) & $38(41.8 \%)$ & 14 (42.4\%) \\
\hline Small $(<$ half of the article) & $52(57.1 \%)$ & $19(57.6 \%)$ \\
\hline
\end{tabular}

(Continued)
Table 2 (Continued).

\begin{tabular}{|c|c|c|}
\hline Assessment Item & $\begin{array}{l}\text { Mental } \\
\text { Health } \\
\text { N (\%) }\end{array}$ & $\begin{array}{l}\text { Diabetes } \\
\text { Mellitus N (\%) }\end{array}$ \\
\hline $\begin{array}{l}\text { Image impression } \\
\text { Positive } \\
\text { Neutral } \\
\text { Negative }\end{array}$ & $\begin{array}{l}7(7.7 \%) \\
84(92.3 \%) \\
0(0.0 \%)\end{array}$ & $\begin{array}{l}4(12.1 \%) \\
28(84.8 \%) \\
1(3.0 \%)\end{array}$ \\
\hline Content analysis & & \\
\hline $\begin{array}{l}\text { Article type* } \\
\text { General news } \\
\text { Awareness } \\
\text { MH services } \\
\text { Informative report } \\
\text { Commentary } \\
\text { Personal stories } \\
\text { Business/economy } \\
\text { Other }\end{array}$ & $\begin{array}{l}63(49.6 \%) \\
15(11.8 \%) \\
5(03.9 \%) \\
40(31.5 \%) \\
3(2.4 \%) \\
0(0.0 \%) \\
0(0.0 \%) \\
2(1.57 \%)\end{array}$ & $\begin{array}{l}18(34.6 \%) \\
20(38.5 \%) \\
9(17.3 \%) \\
26(50.0 \%) \\
3(5.8 \%) \\
0(0.0 \%) \\
0(0.0 \%) \\
0(0.0 \%)\end{array}$ \\
\hline $\begin{array}{l}\text { News source* } \\
\text { National } \\
\text { International } \\
\text { Not applicable }\end{array}$ & $\begin{array}{l}63(49.6 \%) \\
21(16.5 \%) \\
43(33.9 \%)\end{array}$ & $\begin{array}{l}39(75.0 \%) \\
\text { I (1.9\%) } \\
12(23.1 \%)\end{array}$ \\
\hline $\begin{array}{l}\text { Article topics* } \\
\text { MH/DM care system/service } \\
\text { MH/DM events } \\
\text { MH/DM causes } \\
\text { MH/DM treatments } \\
\text { MH/DM symptoms } \\
\text { Side effects of treatments } \\
\text { Dangerousness } \\
\text { Other }\end{array}$ & $\begin{array}{l}27(21.3 \%) \\
26(20.5 \%) \\
24(18.9 \%) \\
41(32.3 \%) \\
16(12.6 \%) \\
1(0.8 \%) \\
4(3.2 \%) \\
53(41.7 \%)\end{array}$ & $\begin{array}{l}15(28.9 \%) \\
26(50.0 \%) \\
6(11.5 \%) \\
12(23.1 \%) \\
8(15.4 \%) \\
4(7.7 \%) \\
1(1.9 \%) \\
35(67.3 \%)\end{array}$ \\
\hline $\begin{array}{l}\text { Included quotation(s) } \\
\text { Yes } \\
\text { No }\end{array}$ & $\begin{array}{l}110(86.6 \%) \\
17(13.4 \%)\end{array}$ & $\begin{array}{l}42(80.8 \%) \\
10(19.2 \%)\end{array}$ \\
\hline $\begin{array}{l}\text { Source of quotation(s)* } \\
\text { Expert } \\
\text { People with mental illness/DM } \\
\text { Family/Friends } \\
\text { Others }\end{array}$ & $\begin{array}{l}93(84.5 \%) \\
7(6.4 \%) \\
3(2.7 \%) \\
43(39.1 \%)\end{array}$ & $\begin{array}{l}37(88.1 \%) \\
2(4.8 \%) \\
0(0.0 \%) \\
14(33.3 \%)\end{array}$ \\
\hline $\begin{array}{l}\text { Overall impression/Discourse tone } \\
\text { Positive } \\
\text { Neutral }\end{array}$ & $\begin{array}{l}31(24.4 \%) \\
96(75.6 \%)\end{array}$ & $\begin{array}{l}18(34.6 \%) \\
34(65.4 \%)\end{array}$ \\
\hline
\end{tabular}

Note: *Multiple answers are possible.

Abbreviations: $\mathrm{N}$, number of articles; \%, percentage; $\mathrm{MH}$, mental health; DM, diabetes mellitus.

Let's talk". However, little attention was given to other conditions that are often misunderstood and stigmatized, such as schizophrenia. Several studies have demonstrated a contribution of the media in the 
stigmatization and the negative perceptions surrounding schizophrenia. ${ }^{25-28}$

Second, that general news in relation to mental health are the most frequent type of articles reported in Qatar's newspapers. Although the majority of general news in this study were in relation to mental health events or campaigns happening in the community, and thus, carrying a neutral tone, non-local news related to mental health often provided negative portrayals of mental illness, such as associations between mental disorders with violence and crime. In addition, the size of some news articles about violence and crime related to mental illness were larger and occupying more than half of a page. Although these articles did not describe local news, this negative media coverage can contribute to the rejection, discrimination, and stigmatization of people with mental illness. Similar findings have been reported in other studies in the Arabian Gulf region. ${ }^{17,29}$

Third, that there is a tendency to favor attractiveness in the headlines, rather than providing informative content about mental illness. Using images that have an eyecatching effect has been reported to positively support the readability and perception of the content in written media. ${ }^{19}$ Although images were included in the majority of the mental health-related articles, these were mostly photographs, logos, or advertisements of events, which overall, did not provide a meaningful connection to the content of the articles. It has also been suggested that the position of where the mental health article is placed in the newspaper is an indicator of how important is the topic of mental health for the media. ${ }^{30}$ The majority of the mental health articles in this study were not located in the first or last pages, and even those that were on the first page, were mostly related to advertisements of upcoming events or about the provision of mental health services.

Other important findings in this study worth highlighting is that almost one-third of articles covered mental health treatments. In a similar Australian study, only around three percent of articles in three different daily newspapers covered this topic. ${ }^{30}$ Our content analysis of the articles covering mental health treatments revealed that these focused mostly on non-pharmacological (natural or alternative) therapies rather than on medications. There was also low coverage about religious or spiritual healing as mental health treatments. This was an interesting finding, considering that previous studies conducted in the general population in Qatar reported that around $40 \%$ believed on spiritual healers to treat mental illness. ${ }^{12,13}$ Results of a study in
Saudi Arabia also reported less coverage about spiritual approaches as compared to new psychological and pharmacological treatments. ${ }^{29}$

The majority of the newspaper articles included quotations derived from experts in the field of mental health. This strategy in reporting suggests an intent to demonstrate responsible journalism practices as well as providing some degree of reliability and trustworthiness to the information published. However, quotations from people with a mental health condition or their families were rarely included in these articles. Previous studies have also shown an overall under-representation of opinions from those experiencing mental illness. ${ }^{24,31}$ Studies in Qatar have shown that the general public possesses misconceptions and non-optimal attitudes towards people with a mental health condition. ${ }^{12,13}$ Including the perspectives of people with mental illness into media reports, "humanizes" mental illness by emphasizing it is real, common, and treatable. ${ }^{31,32}$

\section{Strengths and Limitations}

Several points of strength support the quality of this study. First, we selected Qatari newspapers that have high visibility and readability. As such, all papers were first hand-searched according to the set criteria and complemented by electronic keyword searching, potentially increasing the yield of articles. Two investigators independently performed the search and rated the articles, and findings discussed with a third investigator to resolve any uncertainties. This strengthened the validity of the findings by triangulation.

This study has some limitations. First, the year in which the study was conducted (2017) could have generated unintentional bias in retrieving more positive mental health articles as it coincided with important awareness campaigns in relation to mental health. In addition, this study focused on newspapers and did not assess television or radio representations of mental illness. Lastly, the coding schema used to assess the portrayal of mental illness was not validated, although it was derived from other studies which used similar methodologies. ${ }^{20}$

\section{Conclusions}

Four reputable English and Arabic newspapers were reviewed for their coverage of mental health topics and its treatments over one-year period. Analysis of the retrieved articles revealed a predominantly informative content, with mostly a neutral and non-stigmatizing tone except for nonnational news that often linked mental illness with dangerousness or violence. Although overall encouraging findings, 
there is a need to: 1) increase representation of people with mental illness in print media, 2) increase awareness and scientific reporting on the diversity of treatments available (particularly medications), and 3) collaborate with the media to improve reporting to raise awareness of highly stigmatized mental health conditions such as schizophrenia.

\section{Funding}

The study was funded by Undergraduate Student Grant from Qatar University (QUST-CPH-SPR $\backslash 2017-11$ ).

\section{Disclosure}

All authors declare that they have no conflicts of interest for this work.

\section{References}

1. World Health Organization (WHO). Mental health disorders. [Internet]. Available from: https://www.who.int/mental_health/man agement/en/. Accessed October 16, 2020.

2. Rehm J, Shield KD. Global burden of disease and the impact of mental and addictive disorders. Curr Psychiatry Rep. 2019;21 (2):10. doi:10.1007/s11920-019-0997-0

3. Henderson C, Evans-Lacko S, Thornicroft G. Mental illness stigma, help seeking, and public health programs. Am J Public Health. 2013;103(5):777-780. doi:10.2105/AJPH.2012.301056

4. Thornicroft G. Most people with mental illness are not treated. Lancet. 2007;370(9590):807-808. doi:10.1016/S0140-6736(07) 61392-0

5. Edney DR Mass media and mental illness: a literature review. Ontario: Canadian Mental Health Association. [Internet]; 2004. Available from: https:/ontario.cmha.ca/wp-content/files/2012/07/ mass_media.pdf. Accessed October 16, 2020.

6. Corrigan PW, Penn DL. Lessons from social psychology on discrediting psychiatric stigma. Am Psychol. 1999;54(9):765-776. doi:10.1037/0003-066X.54.9.765

7. Pescosolido BA, Medina TR, Martin JK, Long JS. The "backbone" of stigma: identifying the global core of public prejudice associated with mental illness. Am $J$ Public Health. 2013;103(5):853-860. doi:10.2105/AJPH.2012.301147

8. Rüsch N, Angermeyer MC, Corrigan PW. Mental illness stigma: concepts, consequences, and initiatives to reduce stigma. Eur Psychiatry. 2005;20(8):529-539. doi:10.1016/j.eurpsy.2005.04.004

9. Sewilam AM, Watson AMM, Kassem AM, et al. Suggested avenues to reduce the stigma of mental illness in the Middle East. Int $J$ Soc Psychiatry. 2015;61(2):111-120. doi:10.1177/0020764014537234

10. Zolezzi M, Alamri M, Shaar S, Rainkie D. Stigma associated with mental illness and its treatment in the Arab culture: a systematic review. Int J Soc Psychiatry. 2018;64(6):597-609. doi:10.1177/ 0020764018789200

11. Ministry of Public Health. Your mind matters. A resource to support good mental health and wellbeing for the people of Qatar. [Internet]. Available from: https://sehanafsia.moph.gov.qa/English/Pages/ default.aspx. Accessed October 22, 2020.

12. Bener A, Ghuloum S. Gender differences in the knowledge, attitude and practice towards mental health illness in a rapidly developing Arab society. Int J Soc Psychiatry. 2011;57(5):480-486. doi:10.1177/ 0020764010374415
13. Bener A, Ghuloum S. Ethnic differences in the knowledge, attitude and beliefs towards mental illness in a traditional fast developing country. Psychiatr Danub. 2011;23(2):157-164.

14. Zolezzi M, Bensmail N, Zahrah F, Khaled SM, El-Gaili T. Stigma associated with mental illness: perspectives of university students in Qatar. Neuropsychiatr Dis Treat. 2017;13:1221-1233. doi:10.2147/ NDT.S132075

15. Maiorano A, Lasalvia A, Sampogna G, Pocai B, Ruggeri M, Henderson C. Reducing stigma in media professionals: is there room for improvement? Results from a systematic review. Can J Psychiatry. 2017;62(10):702-715. doi:10.1177/0706743717711172

16. Clement S, Lassman F, Barley E, et al. Mass media interventions for reducing mental health-related stigma. Cochrane Database Syst Rev. 2013;7:CD009453.

17. Elzamzamy K, Alsiddiqi A, Khalil A, Elamin H, Abdul Karim M, Wadoo O. Newspaper depiction of mental and physical health in Qatar. B J Psychol Int. 2020:1-4. Cambridge University Press. doi:10.1192/bji.2020.11

18. National Alliance on Mental Illness (NAMI). Mental health conditions. [Internet]. Available from: https://www.nami.org/learn-more /mental-health-conditions. Accessed October 16, 2020.

19. Busa MG. Introducing the Language of the News: A Student's Guide. New York: Routledge; 2013.

20. Chen M, Lawrie S. Newspaper depictions of mental and physical health. B J Psychol Bull. 2017;41(6):308-313. doi:10.1192/pb.bp.116.054775

21. Syed MA, Alnuaimi AS, Zainel AJ, et al. Prevalence of non-communicable diseases by age, gender and nationality in publicly funded primary care settings in Qatar. BMJ Nutr Prev Health. 2019;2:20-29. doi:10.1136/bmjnph-2018-000014

22. Thornicroft A, Goulden R, Shefer G. Newspaper coverage of mental illness in England 2008-2011. Br J Psychiatry. 2013;202(Suppl 55): S64-S69. doi:10.1192/bjp.bp.112.112920

23. Whitley R, Berry S. Trends in newspaper coverage of mental illness in Canada: 2005-2010. Can J Psychiatry. 2013;47(7):609-610.

24. McGinty EE, Kennedy-Hendricks A, Choksy S, Barry CL. Trends in news media coverage of mental illness in the United States: 1995-2014. Health Aff (Millwood). 2016;35(6):1121-1129. doi:10.1377/hlthaff.2016. 0011

25. Boke O, Aker S, Aker AA, Sarisoy G, Sahin AR. Schizophrenia in Turkish newspapers. Soc Psychiatry Psychiatr Epidemiol. 2007;42 (6):457-461. doi:10.1007/s00127-007-0198-8

26. Dubugras MT, Evans-Lacko S, Mari Jde J. A two-year cross-sectional study on the information about schizophrenia divulged by a prestigious daily newspaper. J Nerv Ment Dis. 2011;199(9):659-665. doi:10.1097/NMD.0b013e318229cf90

27. Vahabzadeh A, Wittenauer J, Carr E. Stigma, schizophrenia and the media: exploring changes in the reporting of schizophrenia in major U.S. newspapers. J Psychiatr Pract. 2011;17(6):439-446. doi:10.1097/01. pra.0000407969.65098.35

28. Koike S, Yamaguchi S, Ojio Y, Ohta K, Ando S. Effect of name change of schizophrenia on mass media between 1985 and 2013 in Japan: a text data mining analysis. Schizophr Bull. 2016;42(3):552-559.

29. McCrae N, Sharif L, Norman I. Media portrayals of mental disorder in Saudi Arabia: a review of popular newspapers. Transcult Psychiatry. 2019;56:428-442. doi:10.1177/1363461518819117

30. Kenez S, O'Halloran P, Liamputtong P. The portrayal of mental health in Australian daily newspapers. Aust NZ J Public Health. 2015;39(6):513-517.

31. Bilić B, Georgaca E. Representations of "mental illness" in Serbian newspapers: a critical discourse analysis. Qual Res Psychol. 2007;4 (1-2):167-186. doi:10.1080/14780880701473573

32. Srivastava K, Chaudhury S, Bhat PS, Mujawar S. Media and mental health. Ind Psychiatry J. 2018;27(1):1-5. doi:10.4103/ipj.ipj_73_18 


\section{Publish your work in this journal}

Psychology Research and Behavior Management is an international, peer-reviewed, open access journal focusing on the science of psychology and its application in behavior management to develop improved outcomes in the clinical, educational, sports and business arenas. Specific topics covered in the journal include: Neuroscience, memory and decision making; Behavior modification and management; Clinical applications; Business and sports performance management; Social and developmental studies; Animal studies. The manuscript management system is completely online and includes a very quick and fair peer-review system, which is all easy to use. Visit http://www. dovepress.com/testimonials.php to read real quotes from published authors. 